\title{
TEATRO PLAYBACK: A HISTÓRIA QUE AS HISTÓRIAS CONTAM ${ }^{1}$
}

O teatro playback é uma forma de teatro em que as pessoas da plateia são convidadas a contar histórias pessoais que serão encenadas pelos atores e músicos. Criado em 1975 por Jonathan Fox, possui um caráter comunitário visto que valoriza e coletiviza as histórias contadas. Este artigo busca explicar o que é o teatro playback e como esse caráter comunitário se concretiza na sua prática.

Palavras-chave: teatro playback, teatro comunidade, histórias pessoais.

Abstract

Playback theatre is a form of theater where people in the audience are invited to tell personal stories that will be performed by actors and musicians. Created in 1975 by Jonathan Fox, it has a community character that enhances and collectivize the stories. This article attempts to explain what is playback theater and how that community character is realized in practice.

Keywords: playback theater, community theater, personal stories 
E então uma menina de 11 a 12 anos levantou a mão querendo contar uma história. Sentou-se na cadeira do narrador e contou da avó que havia morrido, da qual ela sentia muita falta. A avó, antes de morrer, contava de como era no seu tempo em que ela andava de trem, e que um dia a levaria para passear de trem também. Ela nunca foi, porém naquele dia lembrou da história, pois viu o museu reformado (uma antiga estação de trem, onde acontecia a apresentação de teatro). A menina escolheu a atriz que faria o seu papel. $\mathrm{O}$ condutor anunciou o início da cena: "Vamos ver!" A música começou, os atores prepararam o cenário utilizando caixotes de madeira e panos. Os outros personagens foram incorporados pelos outros atores, e sem combinação nenhuma entre os artistas, a história foi encenada, e nela a avó vai embora, se despedindo da neta no final. No término da encenação, a menina chorava. As pessoas que assistiam também se emocionaram. O condutor abraçou a menina e a levou de volta para a plateia. Logo uma mulher se levantou e quis contar uma história alegre, que segundo ela, era "para descontrair". ${ }^{3}$

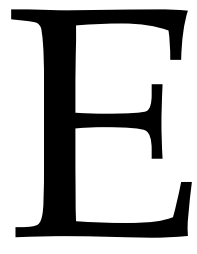

ste é um breve relato de uma história contada em uma apresentação de teatro playback. O teatro playback (ou playback theatre como é conhecido mundialmente) é uma forma teatral em que um grupo de atores, com a mediação de um condutor ${ }^{4}$, encena histórias contadas por pessoas da plateia. Numa apresentação como essa, a interação entre os performers (atores, músicos e condutor) e as pessoas da

1 Artigo extraído da Dissertação de Mestrado da autora: Nossas Histórias em Cena:Um Encontro com o Teatro Playback, 2009.

2 Mestre em Teatro pela UDESC sob a orientação da Prof. Dra. Márcia Pompeo Nogueira. Formada em Psicologia pela Associação Catarinense de Ensino. Atriz da Dionisos Teatro em Joinville - SC desde 2000, onde atua em peças de teatro, como professora de teatro e como condutora e atriz de Teatro Playback.

3 Relato da apresentação de teatro playback realizada no dia 20 de setembro de 2008 pela Dionisos Teatro feito por mim na função de atriz.

40 termo utilizado em traduções anteriores para esta função é diretor (SALAS, 2000). Optou-se, porém, pelo termo condutor, pois em inglês utiliza-se conductor, que aponta para dois aspectos desta tarefa: o trabalho do maestro de uma orquestra, que deve conduzir harmonicamente um grupo de artistas; e também a necessidade de conduzir energia entre todos os participantes. plateia é fundamental para a criação de um espaço onde as histórias pessoais possam ser improvisadas em cena.

Toda a estrutura de uma apresentação possui uma forma já bem definida, que foi sendo aperfeiçoada desde sua criação. De acordo com Fox (1999a, p. 10), criador da prática, desde o início as apresentações do teatro playback aconteciam em escolas, hospitais e centros comunitários.

Foi a prática desde o início feita em espaços diferentes do teatro, para pessoas diferentes das plateias convencionais do teatro que o diferenciou de outras formas teatrais. $O$ fato de que essas audiências pertenciam a contextos específicos, como por exemplo educação/escola, reabilitação/ casa grupo, comunidade/ vizinhança emergiu como um aspecto definidor do método de teatro playback ${ }^{5}$ (DENNIS, 2004, p.28).

Assim, com o foco voltado para espaços alternativos e plateias diversificadas, visando a criação de um momento íntimo e artístico entre os participantes, o teatro playback adquire um formato versátil e ritualístico.

A versatilidade está no fato de que uma apresentação de teatro playback pode acontecer em espaços variados, pois seu formato exige poucos elementos. Um grupo, formado pelos atores, músicos e condutor, utiliza geralmente apenas instrumentos musicais, caixotes e panos coloridos (ou adereços, conforme a preferência do grupo) para a realização de uma apresentação. Isso não exclui a possibilidade de uma apresentação acontecer em um teatro convencional, utilizando-se de iluminação cênica, por exemplo. Porém, é necessário apenas um ambiente não muito grande, em que as pessoas sintam-se confortáveis e próximas ao local de representação.

5 It was the early application in places other than theatres, for people other than conventional theatre audiences that differentiated it from other forms of theatre. That these audiences were situated in specific contexts, e.g., education/school, rehabilitation/group home, community/ neighbourhood, has emerged as a defining aspect of the Playback Theatre method. 
A montagem básica do espaço cênico é bastante simples. À esquerda da plateia - à direita do palco - são colocadas duas cadeiras lado a lado, voltadas em direção ao centro, para o diretor e para o narrador. [...] No outro lado do palco está o assento do músico e um conjunto de instrumentos espalhados sobre uma mesa baixa ou um pano aberto no chão. Na parte de trás estão alguns engradados ou caixotes de madeira para os atores se sentarem e, mais tarde, utilizarem como acessórios durante a encenação (SALAS, 2000, p. 114)

Para Rowe (2007, p. 51), assim que a plateia vem chegando, ela já vai sendo apresentada ao playback de acordo com a disposição das cadeiras, as luzes, a relação com os atores. Seu nível de segurança psicológica dependerá de alguns aspectos: "Isso [a segurança em contar histórias] será crucialmente afetado pelo tamanho da plateia e a familiaridade que têm entre si, qualquer interação com os performers, a visão que tem do palco, e, principalmente, a integridade do limite entre o espaço teatral e o de fora" 6 (ROWE, 2007, p. 51).

Por isso, o ritual é um aspecto importante nesse tipo de teatro. É necessária a criação de um ambiente aconchegante, onde as histórias possam ser compartilhadas. É muito difícil alguém contar uma história pessoal diante de uma plateia de desconhecidos, sem antes haver uma preparação, sem haver a construção de um espaço seguro em que as regras estejam estabelecidas.

No playback theatre o ritual significa uma repetição de estruturas de espaço e de tempo que proporcione estabilidade e familiaridade, dentro das quais o imprevisível pode estar contido. O ritual serve também para ajudar a atingir uma percepção intensificada da experiência; é essa intensificação da percepção que pode transformar a vida em teatro (SALAS, 2000, p. 118).

6 This will be crucially affected by the size of the audience and their familiarity whith each other, any interaction with the performers, the view they have of the stage and, crucially, the integrity of the boundary between the theatre space and the outside.
Como forma de estabelecimento deste ritual, é necessário que uma apresentação seja bem conduzida, tendo uma estrutura concisa. No mundo todo, o teatro playback possui essa estrutura já bem estabelecida. Apesar das diferenças de um grupo para outro, de forma geral a sequência de uma apresentação possui invariavelmente alguns passos: apresentação inicial, explicação da forma, cenas curtas realizadas a partir de sentimentos das pessoas na plateia, narração de histórias, encenação das histórias, encerramento.

Uma apresentação consiste então num momento inicial em que o grupo se apresenta, assim como também muitas vezes as pessoas da plateia, e o condutor explica "as regras do jogo", ou seja, fala como funciona o teatro playback.

O diretor sabe que uma de suas primeiras tarefas é explicar às pessoas novas o que é o playback e mostrar que se trata de um lugar seguro para contar suas histórias. É muito importante ter um ritual de abertura, tanto para as pessoas que frequentam regularmente quanto para aquelas que estão ali pela primeira vez. $\mathrm{O}$ diretor deve ressaltar que as histórias reais de pessoas comuns são valiosas para serem compartilhadas em público e para receberem um tratamento artístico (SALAS, 2000, p. 43).

O ritual de abertura é próprio de cada grupo. Alguns iniciam com uma música, outros com os atores cantando em coro, outros já com a fala do condutor. Também a forma como se apresentam à plateia difere bastante. Um ponto importante nessa apresentação, é que ela seja o momento de "quebrar o gelo", de dizer à plateia que ela também será responsável pelo espetáculo, que a sua participação é tão importante quanto a ação dos atores. É necessário apontar a ideia de que todos são seres humanos que podem compartilhar histórias, que farão parte de uma experiência da qual ninguém sabe qual será o resultado. É o momento de sinalizar que haverá tanto a exposição das pessoas ao contar suas histórias pessoais, como dos 
atores na improvisação. Para tanto, tornouse imprescindível no teatro playback que os performers também se apresentem com suas histórias e sentimentos. Dessa forma, é comum que as primeiras cenas sejam feitas a partir da fala deles. Assim a plateia começa a se familiarizar com a forma. Com os performers também falando de si, fica mais clara a ideia de diálogo que o teatro playback carrega. $\mathrm{O}$ público logo fica sabendo que não é uma via de mão única, onde sua participação será "utilizada" para gerar um show de puro entretenimento; mas sim que deve haver uma troca, onde ambas as partes colaboram e são gratificadas.

Após a apresentação inicial e antes da encenação das histórias, o condutor pergunta às pessoas da plateia como estão se sentindo no momento. Nessa hora são utilizadas as chamadas cenas ou formas curtas (short forms) do teatro playback (ROWE, 2007, p. 193). Tratam-se de cenas rápidas, que possuem formas variadas, feitas a partir do que as pessoas dizem estar sentindo no momento. Elas servem como um aquecimento, para que a plateia comece a participar. Geralmente as pessoas ficam ansiosas ao saber que haverá interação num espetáculo de teatro. Com as formas curtas, a apresentação ganha agilidade e a atenção da plateia, além de ser uma forma para que essa plateia tome conhecimento de como será a sua participação.

Sempre ao final de uma forma curta, quando a música para, os atores saem de suas posições e se voltam para a pessoa que falou o sentimento ou a história. Trata-se de um olhar carinhoso, como que oferecendo a cena feita como um presente para o narrador. Também o condutor o faz, dando oportunidade para que a pessoa possa expressar mais alguma coisa em relação à cena ou como se sentiu vendo-a.

Após a apresentação inicial e o aquecimento com formas curtas, entrase no momento mais importante de uma apresentação de teatro playback: a encenação de histórias. Esse é um momento que deve ser bem construído pelo condutor. Ele deve anunciar esse momento, falar da importância das histórias, do respeito que se deve ter com elas. É aqui também que o condutor apresenta a cadeira do contador de histórias. Até então as pessoas falavam sentadas de seus lugares. Porém, neste momento, as pessoas são convidadas a sair de seus lugares, sentar numa cadeira especial, ao lado do condutor, e contar sua história. O condutor deve enfatizar que a história deve ser algo que aconteceu com a pessoa que vai contá-la. Não precisa ser uma história importante ou triste ou alegre. Todas as histórias são bem-vindas. Isso é o que preconiza o teatro playback.

\begin{abstract}
Estamos dizendo, também, que a expressão artística eficaz não é domínio exclusivo do ator profissional; todos nós, inclusive você e eu, temos elementos dentro ou fora de nós mesmos - para criar algo belo que pode atingir outros corações. Por si só, uma história é da mais profunda importância; precisamos de histórias em nossas vidas para construir significados (SALAS, 2000, p. 24).
\end{abstract}

Assim que a pessoa senta na cadeira do narrador, a entrevista tem início. $\mathrm{O}$ condutor faz as perguntas de modo que a história fique clara para os atores e para a plateia. $\mathrm{O}$ narrador escolhe os atores que farão as personagens da história.

O condutor, neste momento, tem uma tarefa difícil. Ele deve, além de conversar com o narrador, ouvir sua história, fazer as perguntas necessárias para clarificar a narrativa; deve também abrir essa conversa para a plateia. É sua função fazer com que a plateia compreenda a história, que muitas vezes é contada em voz baixa pelo narrador.

O trabalho do diretor [condutor] é o de descobrir o que é, deslocar a história de seu lugar na memória do narrador para o âmbito público e dar-lhe forma antes de entregá-la aos atores, para que se torne um artefato vivo, que os outros possam ver, entender, lembrar e ser transformados por ela (SALAS, 2000, p. 89). 
Fazer as perguntas certas neste momento é fundamental para o bom andamento da cena e da apresentação como um todo. O condutor deve procurar o "quem", o "onde", o "quando" e o "o quê" da história. Busca também elementos dos personagens e, segundo Salas (2000), a essência da história.

\begin{abstract}
A essência da história nos dá o núcleo em torno do qual sua forma é construída. Ela funciona como um princípio organizador que pode trazer não somente coerência como também grande profundidade para a cena. O senso de história do diretor [condutor] vai ser um dos fatores mais importantes do sucesso da cena - sucesso tanto em termos de arte quanto da verdade humana, que são inseparáveis neste trabalho (SALAS, 2000, p. 92).
\end{abstract}

Quando a entrevista é encerrada, o condutor pode dar ou não indicações de cena para os atores e, ao final, fala o tradicional "Vamos ver!". Esse é o sinal para que os atores improvisem a história contada. A música começa, e os atores, sem combinações, vão arrumar a cena, utilizando ou não panos, acessórios e/ou caixotes. À medida que vão ficando prontos, os atores começam a ficar imóveis. Quando todos param, a música para também e a cena tem início.

Durante a encenação da história, o músico improvisa com os atores. A ideia no teatro playback é tentar ser o mais fiel possível à história contada. É necessário recordar os nomes, a sequência dos fatos, tentando utilizar somente os personagens que apareceram na narrativa. Estar atento ao início e ao final da história. Porém, muitas vezes faltam informações, e mesmo os diálogos para serem improvisados necessitam da criação e intuição dos atores. Para tanto, é necessário muito cuidado para não inserir elementos que fujam ao universo do narrador e da história.

Ao final da cena, os atores se voltam para o narrador e o condutor pergunta se a cena contemplou a sua história. Às vezes, se ele não fica satisfeito com a cena, esta pode ser corrigida, ou seja, os atores a refazem de acordo com as indicações do narrador.

A finalização de uma apresentação é também um momento importante e delicado. É o condutor que comanda o tempo de uma apresentação e "sente" a plateia, para saber se mais uma história deve ser contada ou não. Uma apresentação pode ser encerrada com alguma forma curta, ou com uma fala do condutor que contemple as histórias contadas. Os grupos utilizam também a música para finalizar uma apresentação. "Quando termina o espetáculo, a finalização que você fizer também vai ajudar a afirmar o significado e a dignidade daquilo que todos acabaram de compartilhar" (SALAS, 2000, p. 117).

Não há, a princípio, no teatro playback, o intuito de abrir uma discussão sobre "as mensagens" ou "a moral" das histórias contadas em uma apresentação. Se há a necessidade de fazer uma finalização da apresentação e do condutor falar, esta fala é para apenas retomar o que aconteceu e que foi compartilhado por todos. Há algo que os praticantes de teatro playback chamam de red thread (fio [da meada] vermelho). ${ }^{7}$ É a ideia de que as histórias "conversam" entre si, uma respondendo a outra. Pode-se achar o fio condutor de uma apresentação através do "diálogo" que as histórias estabelecem entre si. Qual a história que as histórias contam? É a essa pergunta que o condutor e o grupo respondem para finalizar uma apresentação.

O teatro playback não comenta ou julga, não há explicação ou entendimento com palavras e termos. Nós apenas assistimos. Isso nos coloca em um diferente estado de consciência muitorapidamente. Um pequeno transe é criado. Nós começamos a "pensar" em histórias e imagens, nós assistimos e adicionamos histórias para outras histórias,

7 Segundo HOESCH (1999), red thread é uma metáfora inspirada na tecelagem, em que um fio vermelho é usado para que o tecelão siga o padrão. É um dito comum alemão usado para significar "o elemento que conecta". 
encaixamos imagens para imagens sem que nosso processo racional primário entre em ação ${ }^{8}$ (HOESCH, 1999, p. 54).

Hoesch (1999) defende que além de uma história se conectar com outra como uma resposta, elas ainda oferecem padrões de solução e transformação. Portanto, o teatro playback, mesmo não sendo psicoterapia, teria um poder restaurativo (healing), tanto para o indivíduo como para o grupo.

Fox (1999b, p. 117) também comenta a red thread, apontando que as histórias dialogam entre si, fazendo contraponto umas às outras. Para ele, há mais de uma red thread, são várias as mensagens que são comunicadas através das cenas, com movimento, música e cor.

$\mathrm{O}$ jeito como as red threads funcionam em um evento de playback é tão rico que, como condutor, eu deixo o processo seguir tão indireto quanto possível, preocupado que se faço muitas sugestões, eu posso de fato restringir essa forma de diálogo geralmente inconsciente $^{9}$ (FOX, 1999b, p. 118).

Outro aspecto é que o contexto influencia as histórias a serem contadas. "Aprendemos que os elementos da história, ao falar com a comunidade de forma geral, geralmente estão relacionados muito especificadamente às circunstâncias do grupo"10 (FOX, 1999b, p. 118).

Por fim, uma garota, amiga da menina que contou a primeira história, pediu para contar uma também. Contou o dia em que elas se conheceram. Logo começou

8 Playback theatre does not comment or judge, there is no explanation or understanding with words and terms. We just watch. That puts us in a different state of consciousness very quickly. A slight trance is created. We begin to 'think' in stories and pictures, we watch and add stories to other stories, fit pictures to pictures without our rational primary process getting started.

9 The way the red threads carry through a playback event is so rich that as conductor I like to let the process be as undirected as possible, worried that if I make too many suggestions, I will in fact restrict this often unconscious form of dialogue.

10 We have learned that the story elements, in addition to speaking to the community in a general way, usually relate very specifically to the circumstances of the group. a chorar contando a história. Falou que era sozinha e a amiga veio fazer o lanche com ela. Depois ficaram "amigas para sempre". Um dia ela foi na casa da amiga e descobriu pela avó dela (aquela da outra história) que eram primas. Fizemos a história na forma curta "Narrativa em $\mathrm{V}^{\prime \prime}$. A garota, ainda comovida talvez com a história da amiga, quis contar algo para exaltá-la. Para o grupo esta apresentação foi o maior exemplo até agora de como as histórias se comunicam, e como as pessoas também se responsabilizam pelos outros e pelo bom andamento do trabalho. ${ }^{11}$

Para Fox (1999b, p. 119) as histórias possuem uma forma muito especial de discussão, que acontece através das cenas no palco. Há mais ação do que palavras. Pode haver ideias nas histórias, pode-se até encontrar a moral de algumas delas. Porém, o mais importante é que elas são histórias com personagens e imagens. "E como nas histórias, o valor, ou significado, geralmente se revela apenas indiretamente"12 (FOX, 1999 b, p. 119). Os valores e/ou mensagens vão se construindo para a plateia durante as cenas, e não através de análise racional e/ou interpretação de significados. Não há falas ou julgamentos sobre cenas e histórias, apenas umas após as outras as histórias e cenas vão se completando ou se opondo. $\mathrm{A}(\mathrm{s})$ red thread(s) dão a transversalidade de uma apresentação, e podem ser explicitadas pelo condutor ao final, buscando a história que as histórias contaram.

\section{Teatro playback: construindo comunidades}

O Centro de Playback theatre em New Paltz, fundado por Jonathan Fox, é a maior referência desta prática atualmente. É um centroque promovecursos e dá assistência a diversos grupos pelo mundo com o intuito de promover o teatro playback. O seu primeiro objetivo é "encorajar e

11 Relato da apresentação de teatro playback realizada no dia 20 de setembro de 2008 pela Dionisos Teatro feito por mim na função de atriz.

12 And as in stories, the value, or meaning, often reveals itself only indirectly. 
fomentar os direitos humanos individuais e o diálogo comunitário através do teatro pessoal de improviso facilitando a narração de diversas opiniões, lembranças e histórias; ouvindo; empatia; vitalidade e esperança". ${ }^{13}$

Dessa forma, apesar das várias mudanças que o teatro playback pode ter sofrido desde sua criação, a ideia de que seja um teatro voltado para realizar uma conexão entre as pessoas permanece. Salas (2000, p. 36) coloca essa questão de forma clara, apontando o teatro playback como edificador de comunidades:

\begin{abstract}
Nossa tarefa no playback theatre é ir além do que normalmente fazemos em nosso modo de contar histórias do cotidiano. Nosso trabalho é revelar a perfeição de formas e o significado de qualquer experiência, mesmo que seja narrada de maneira nebulosa e informe. Conferimos dignidade às histórias, com ritual e consciência estética, interligando-as para que formem uma história coletiva a respeito de determinada comunidade, seja a comunidade transitória constituída pelo público de um espetáculo, seja um grupo de pessoas cujas vidas estejam interconectadas deforma mais continuada. Um grupo de pessoas que compartilha suas histórias deste modo não pode deixar de se sentir conectado: o playback theatre é um poderoso edificador de comunidades. Oferecemos uma arena pública na qual o significado da experiência individual se expande para fazer parte de um sentido compartilhado de existência significativa (SALAS, 2000, p. 36).
\end{abstract}

Assim, independente do lugar e objetivo que esteja sendo empregado, o teatro playback imprime essas característica de promover conexão entre as pessoas.

Segundo Dennis (2007, p. 24) há uma tendência a identificar a plateia do teatro playback como uma "comunidade". Fox (1999b, p. 116) o faz, quando fala que

13 Encourage and foster individual human rights and community dialogue through personal improvisational theatre by facilitating the narration of diverse opinions, recollections and stories; listening; empathy; vitality; and hope. Disponível em: < http://www.playbackcentre.org/ourstory/the-mission/ > Acesso em: 10 jun. 2011. comunidade é o grupo que experiencia o teatro playback, seja numa apresentação com ingresso ou em algum lugar especial como uma escola, local de trabalho ou centro comunitário. Ela ainda afirma que a teoria que está por trás desse entendimento deriva dosociodrama, queé “[...] ummétodo de ação profunda que lida com relações intergrupais e ideologias coletivas" ${ }^{14}$ (FOX apud DENNIS, 2007, p. 24).

O sociodrama baseia-se na suposição tácita de que o grupo formado pela plateia já está organizado pelos papéis culturais e sociais que em algum grau são compartilhados por todos os portadores da cultura. É, portanto, irrelevante quem são os indivíduos, ou de quem o grupo é composto, ou que tamanho tem (FOX, 2002, p. 52).

Assim, segundo a autora, a plateia é considerada como representante de uma comunidade, proveniente de um contexto mais amplo. Essa ideia vem ao encontro do que Salas aponta acima: a comunidade atingida pode ser formada por um grupo que já possui relações continuadas ou simplesmente pelos laços transitórios de uma plateia formada para uma apresentação.

Good (2008) escreve sobre a capacidade que o teatro playback tem em se tornar o espelho de uma comunidade, abrindo espaço para o diálogo. “O diálogo que uma apresentação ou workshop de teatro playback pode abrir não é para resolver problemas; mas sim provê uma oportunidade para que as pessoas aceitem as visões e experiências existentes na comunidade". ${ }^{15}$ (GOOD, 2008, s/p).

A história, que num primeiro momento era uma elaboração somente do autor/ narrador, e que num segundo momento passa a ser imaginada pelas pessoas da plateia que a escutam, após o convite

14 [...] a deep action method dealing with intergroup relations and collective ideologies.

15 The dialogue a Playback performance or workshop can open up is not problem solving; it provides na opportunity for people to accept the existing views and experience of the community. 
"Vamos ver?", é corporificada pelos atores. A história pessoal encenada ganha novos detalhes e adquire uma dimensão artística através do teatro playback. Elas acontecerão novamente não apenas individualmente, mas coletivamente.

Dessa forma, o teatro playback não trata somente de utilizar as histórias contadas para fazer teatro. Trata também da valorização do outro, da valorização dashistórias, daimportância dainteração. Por um lado ele representa um estímulo para ouvirmos as histórias dos outros e para contarmos nossas histórias. Por outro, ele valoriza as histórias contadas colocando-as no centro do palco, em foco. E mesmo aqueles que talvez não tenham a oportunidade de contar uma história durante uma apresentação, irão no mínimo se perguntar "Quais são as minhas histórias? Eu tenho histórias para contar?" Sendo assim, o teatro playback é também um mobilizador de histórias.

Se no teatro em geral, o prazer da plateia está em ver uma cena bem feita, no teatro playback esse prazer não se limita a isso. Existem outros elementos intrínsecos à forma que também proporcionam gratificação: contar uma história, ouvir histórias, o sentimento de que a sua história está sendo valorizada, o estabelecimento de uma relação com as histórias dos outros, seja pela identificação, pelo reconhecimento ou pela rejeição. Dessa forma, o valor estético do playback inclui outras dimensões. Não é somente um texto elaborado, ou a performance de um ator em determinado personagem, ou figurinos e cenários de tirar o fôlego que estão em questão no teatro playback.

O prazer inclui o desafio do improviso: como aqueles atores irão se virar para fazer essa história? Ou talvez esteja em somente reviver a história, lembrá-la, contá-la, vêla novamente. Talvez seja saber que outras pessoas vão ouvir essa minha história e ela não vai mais morrer comigo. Talvez esteja em ouvir as histórias dos outros. De qualquer forma, é tarefa dos artistas proporcionarem espaço para que essas gratificações, sejam elas quais forem, possam acontecer.

Para praticar teatro playback, énecessário entender a plateia e seus narradores como uma comunidade. A estética do playback compreende uma conexão entre as pessoas presentes (performers e público). No lugar de separar os elementos artísticos e outros elementos de caráter social e/ou terapêutico, é necessário o entendimento de que a arte do playback abarca esses elementos. Ela é tudo isso. O que é necessário para um artista praticar teatro playback é dar espaço e voz ao ser humano que está atrás desse artista, que o constitui.

A arte criada no teatro playback é de âmbito coletivo. Rowe (2007, p. 71) cita Bakhtin, quando este fala que o significado não está na palavra, nem na alma de quem fala e nem na alma de quem escuta. Está numa conexão de todos. Isso traz a ideia de que ninguém é dono de um significado, e sim que ele é construído com várias partes. Este conceito tem um grande efeito na conceitualização do playback.

\begin{abstract}
No lugar de uma história 'possuída' pelo narrador, a história no teatro playback se torna não apenas um texto criado em conjunto mas também um texto que é criado na relação com outros textos - um 'intertexto' ${ }^{16}$ (ROWE, 2007, p. 72).
\end{abstract}

Para o autor, as narrativas no playback são então criações negociadas e contextuais. A história do narrador deve ser respeitada, porém ela não é só dele. O playback fica na tensão entre a história que o narrador conta e a transformação ocorrida no contato com os outros elementos (atores, condutor, plateia...) (ROWE, 2007, p. 73).

O que se cria no playback é um teatro que precisa de diálogo, respeito, confiança,

16 It brings into question the notion of the teller as an independent self-transparent originator of meaning and questions the possibility of the independence of their story. Instead of a story 'owned' by the teller, the playback theatre story becomes not only a jointly created text but also a text that is created in relation to other texts - an 'intertext'. 
porque, como coloca Rowe, essa "cria" é coletiva.Elevaigerarmomentosdefrustração, de falhas, de espanto, de ansiedade, de divertimento, de constrangimento, de partilha, de êxtase, e de outros tantos que não se pode controlar na totalidade.

\begin{abstract}
A resposta dos performers no teatro playback é sempre e apenas uma resposta humana para outra história. A performance pode ser maravilhosa, generosa, arriscada e inspirada, mas nunca mais do que humana. [...] $\mathrm{O}$ playback efetivo afrouxa as 'gravatas' da história, abre para outras possíveis interpretações e revela os meios pelos quais nós construímos o sentido de nossa experiência $^{17}$ (ROWE, 2007, p. 39).
\end{abstract}

Nessa troca, o narrador oferece sua história e os performers a sua disponibilidade pessoal e artística para uma cena criada na intersubjetividade, no intertexto. A sua generosidade se mistura com sua técnica vocal, suas memórias pessoais com sua expressão corporal, seus sentimentos com a construção de seu personagem. As técnicas teatrais potencializam esse diálogo.

$\mathrm{O}$ teatro playback se constitui numa prática que pode abranger experiências artísticas, de socialização e de pertencimento, porque carrega em seu bojo a ideia de arte como necessidade humana de encontro e comunhão. "E em qualquer contexto, como apresentação ou de outra forma, há a possibilidade daqueles momentos que nos mostram o cumprimento da promessa do playback: a fusão efêmera e mágica do artístico e do humano"18 (SALAS, 1999, p. 34).

17 The response of the performers in playback theatre is always and only a human response to another's story. The performance can be wonderful, generous, risky and inspired, but it is never more than human. [...] Effective playback loosens the 'ties' of the story, opens up other possible interpretations and reveals the means through which we make sense of our experience.

18 And in any context, performance or otherwise, there is the possibility of those moments that show us the ideal fulfillment of playback's promise; the ephemeral, magical fusion of artistry and humanity.

\section{Referências bibliográficas}

DENNIS, Rea. Public Performance, Personal Story: A Study of Playback Theatre. Griffith University, 2004. Disponível em: <http:// www.playbackschool.org/resources_ longlist.htm> Acesso em: 05 out. 2007.

FOX, Jonathan. Acts of Service: Spontaneity, Commitment, Tradition in the Nonscripted Theatre. New Paltz: Tusitala, 2003.

FOX, Jonathan. Introduction. In: DAUBER, Heinrich; FOX, Jonathan. (org). Gathering Voices: Essays on Playback Theatre. New Paltz: Tusitala, 1999a. (9-16)

FOX, Jonathan. A Ritual for Our Time. In: DAUBER, Heinrich; FOX, Jonathan. (org). Gathering Voices: Essays on Playback Theatre.

New Paltz: Tusitala, 1999b. (116-134)

FOX, Jonathan. Playback Theater: the Community Sees Itself. In: COURTNEY, Richard; SCHATTNER, Gertrud. (ed) Drama In Therapy (2 vols.) New York : Drama Book Specialists, 1982. (295-306).

GOOD, Mary. Who is you neighbour? Playback theatre and Community Development. Disponível em: <www.playbackcentre. org> Acesso em: 06 dez. 2008.

HOESCH, Folma. The red thread: storytelling as a healing process. In: DAUBER, Heinrich; FOX, Jonathan. (org). Gathering Voices: Essays on Playback Theatre. New Paltz: Tusitala, 1999. (p. 46-65)

ROWE, Nick. Playing the Other: Dramatizing Personal Narratives in Playback Theatre. London, Philadelphia: Jessica Kingsley Publishers, 2007.

SALAS, Jo. Entrevista concedida a Fe Day. In: DAY, Fe. Playback Theatre-The Early Years Interview with Jo Salas. Disponível em: <www.playbackcentre.org> Acesso em: 06 dez. 2008. Entrevista.

SALAS, Jo. Playback Theatre: uma nova forma de expressar ação e emoção. São Paulo: Agora, 2000.

SALAS, Jo. What is "good" playback theatre? In: DAUBER, Heinrich; FOX, Jonathan. (org). Gathering Voices: Essays on Playback Theatre. New Paltz: Tusitala, 1999b. (17-35) 